\title{
Carbohydrate-Based Polyesters Made from Bicyclic Acetalized Galactaric Acid
}

\author{
C. Lavilla, $^{\dagger}$ A. Alla, ${ }^{\dagger}$ A. Martínez de Ilarduya, ${ }^{\dagger}$ E. Benito, ${ }^{\ddagger}$ M. G. García-Martín, ${ }^{\ddagger}$ J. A. Galbis, $^{\ddagger}$ and \\ S. Muñoz-Guerra*,+
}

${ }^{\dagger}$ Departament d'Enginyeria Química, Universitat Politècnica de Catalunya, ETSEIB, Diagonal 647, 08028 Barcelona, Spain

${ }^{\ddagger}$ Departamento de Química Orgánica y Farmacéutica, Universidad de Sevilla, Profesor García González 2, 41012 Sevilla, Spain

Supporting Information

ABSTRACT: The dimethyl ester of 2,3:4,5-di-O-methylene-galactaric acid (Galx) was made to react in the melt with $1, n$-alkanediols $\mathrm{HO}\left(\mathrm{CH}_{2}\right)_{n} \mathrm{OH}$ containing even numbers of methylenes ( $n$ from 6 to 12) to produce linear polycyclic polyesters. Two sets of poly(alkylene 2,3:4,5-di-O-methylenegalactarate) polyesters (PE- $n \mathrm{Galx}$ ) with weight-average molecular weights in the $\sim 5000-10000$ and $\sim 35000-45000$ ranges were obtained using TBT and DBTO catalysts, respectively. For comparative purposes a set of poly(alkylene adipate) polyesters (PE-nAd) was also synthesized with molecular weights in the higher range using a similar procedure. The thermal stability of PE- $n$ Galx was greater than that of PE- nAd although it notably decayed as molecular weight

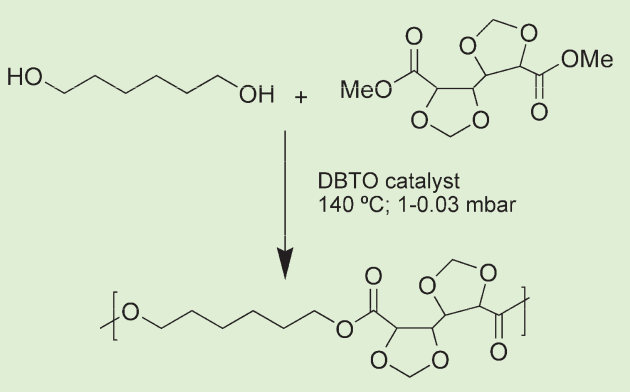
decreased. The replacement of Ad by Galx in the polyesters caused increases in $T_{\mathrm{g}}$ of up to $70{ }^{\circ} \mathrm{C}$, and almost doubled the tensile mechanical parameters. All PE- $n$ Galx were semicrystalline but only those made from 1,12-dodecanediol were able to crystallize from the melt with a crystallization rate that diminished as the molecular weight increased. In general, the galactarate containing polyesters displayed higher solubility and wettability than polyadipates, they hydrolyzed faster and exhibited comparable sensitivity to the action of lipases.

\section{INTRODUCTION}

The development of biobased polymers today is drawing an enormous amount of interest for their potential to reduce the utilization of petrochemicals and to increase the added-value of agriculture products and wastes. ${ }^{1}$ Among the renewable naturally occurring sources, carbohydrates stand out in a privileged position due to their huge abundance and because they are inexhaustible and readily available. A good assortment of monomers based on carbohydrates has been recently explored for making different classes of polymers. ${ }^{2-5}$ The hydroxyl and carboxylic rich functionality of these compounds makes them mostly appropriate for polycondensation in spite of the fact that certain chemical handling for group protection will be required if linear polymers are searched. Carbohydrate-based polycondensates may be provided with a great diversity of chemical structures and unusual properties; they typically display enhanced hydrophilicity, less toxicity, and higher susceptibility to biodegradation than petrochemical-based polycondensates, offering therefore a wide possibility of applications in food packaging and medical devices. $^{6,7}$

Among the wide diversity of sugar-derived monomers that have been recently explored, 1,4:3,6-dianhydrohexitols have drawn particular attention for the synthesis of linear polycondensates. ${ }^{8,9}$ In these hexitols, the four exceeding hydroxyl groups are blocked by intramolecular etherification leading to a bicyclic structure with the secondary 2- and 5-hydroxyl groups standing free for reaction. The interest for monomers having a cyclic structure arises from their capacity for adding stiffness to the polymer chain with the subsequent increasing in $T_{\mathrm{g}} .1,4: 3,6-$ Dianhydro-D-glucitol known as isosorbide (Is) is the only dianhydrohexitol industrially available today because it can be produced from cereal starch through an economically acceptable process. It is composed of two cis-fused nearly planar tetrahydrofuran rings with a dihedral angle of $120^{\circ}$ and the 2- and 5-hydroxyl groups in endo and exo positions, respectively (Figure 1a). Isosorbide has been extensively investigated in the last decades as a convenient building block for diverse polycondensates. ${ }^{10-14}$ In this line, special attention is given to aromatic polyesters and copolyesters, ${ }^{15-17}$ in which Is has proven to successfully replace petrochemical diols without detriment, or even with improvement, of their properties.

In this work we present a new bicyclic carbohydrate-based monomer useful for the preparation of linear polycondensates, specifically for the synthesis of aliphatic polyesters. Dimethyl 2,3:4,5-di-O-methylene-galactarate (Figure $1 \mathrm{~b}$ ), abbreviated as Galx, is the dimethyl ester of galactaric acid with the hydroxyl groups acetalized with formaldehyde. This compound is readily synthesized in one step from commercially available mucic acid

Received: March 31, 2011

Revised: $\quad$ May 2, 2011

Published: May 12, 2011 

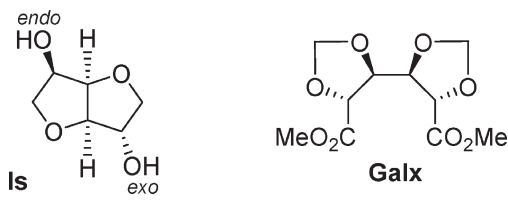

Figure 1. Chemical structures of 1,4:3,6-dianhydrosorbitol (isosorbide, Is) and dimethyl 2,3:4,5-di-O-methylene galactarate (Galx).

(galactaric acid) which in turn is produced from naturally occurring D-galactose or D-galactose-containing compounds by oxidation with nitric acid. ${ }^{18}$ Contrary to isosorbide, Galx is centrosymmetric and therefore does not generate regicity in the growing polymer chain, and its two carboxyl groups display the same reactivity because they are spatially undistinguishable.

The use of acetalized aldaric acid derivatives as building blocks for the synthesis of polycondensates is not new, but most of the cases reported so far refer to polyamides and polyesters derived from acetalized tartaric acid, which contain a dioxolane ring forming part of the polymer backbone. Thus, Muñoz-Guerra et al. ${ }^{19,20}$ have described the synthesis and crystal structure of linear polyamides from di-O-methylene L-tartaric acid and several diamines, and later Kimura et al. ${ }^{21}$ studied their biodegradability. More recently, low molecular weight polyesters made from di-Oisopropylidene L-tartaric acid and alkanediols have been reported. $^{22}$ To our knowledge, bicyclic acetalized aldaric acid derivatives have not been explored for the synthesis of polycondensates to date. It should be mentioned however that 1-deoxy-1-isocyanate-2,3:4,5-di-O-isopropylidene-D-galactitol has been synthesized and used as monomer for the preparation of $[n]$-polyurethanes. ${ }^{23}$

\section{EXPERIMENTAL SECTION}

Materials. Dimethyl 2,3:4,5-di-O-methylene-galactarate was synthesized following the procedure reported by Stacey et al. ${ }^{18}$ The reagents 1,6-hexanediol (97\%), 1,8-octanediol (98\%), 1,10-decanediol (98\%), 1,12-dodecanediol (99\%), dimethyl adipate (>99\%), and the catalysts titanium(IV) tetrabutoxide (TBT, 98\%) and dibutyl tin oxide (DBTO, 98\%) were purchased from Sigma-Aldrich. Solvents used for purification and characterization, as chloroform, methanol, and diethyl ether, and other solvents used in solubility essays, were purchased from Panreac and were all of either technical or high-purity grade. The enzymes used in biodegradation experiments, lipase from porcine pancreas (activity

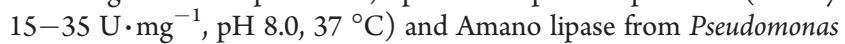
fluorescens (activity $\geq 20 \mathrm{U} \cdot \mathrm{mg}^{-1}, \mathrm{pH} 8.0,55^{\circ} \mathrm{C}$ ) were also purchased from Sigma-Aldrich. One unit (U) was defined as that amount of enzyme that catalyzed the release of fatty acid from triglycerides at the rate of $1 \mu \mathrm{mol} \cdot \min ^{-1}$. All the reagents and solvents were used as received without further purification.

General Methods. ${ }^{1} \mathrm{H}$ and ${ }^{13} \mathrm{C}$ NMR spectra were recorded on a Bruker AMX-300 spectrometer at $25.0^{\circ} \mathrm{C}$ operating at 300.1 and 75.5 $\mathrm{MHz}$, respectively. Polyesters and water degradation products were dissolved in deuterated chloroform or deuterated water, and spectra were internally referenced to tetramethylsilane (TMS) or to the sodium salt of 3-(trimethylsilyl)-propanesulfonic acid. About 10 and $50 \mathrm{mg}$ of sample in $1 \mathrm{~mL}$ of solvent were used for ${ }^{1} \mathrm{H}$ and ${ }^{13} \mathrm{C}$ NMR, respectively. A total of 64 scans were acquired for ${ }^{1} \mathrm{H}$ and $1000-10000$ for ${ }^{13} \mathrm{C}$, with 32- and 64-K data points with relaxation delays of 1 and 2 s, respectively. Elemental analyses were determined in the Microanalysis Laboratories of the CSIC, Barcelona, Spain. FT-IR measurements were carried out in a Jasco 4100 FTIR spectrophotometer, coupled with an ATR accessory
Specac MKII, with a single reflection Golden Gate diamond, ZnSe lenses, and a high stability temperature driver West6100+. The absorbance of the sample was recorded in the range of $4000-550 \mathrm{~cm}^{-1}$ accumulating 32 scans for each run. Intrinsic viscosities of polyesters dissolved in chloroform were measured in an Anton Paar AMVn Automated Micro Viscosimeter at $25.00 \pm 0.01{ }^{\circ} \mathrm{C}$, using the VisioLab for AMVn software. Gel permeation chromatograms were acquired at $35.0{ }^{\circ} \mathrm{C}$ with a Waters equipment provided with a refractionindex detector. The samples were chromatographed with $0.05 \mathrm{M}$ sodium trifluoroacetate-hexafluoroisopropanol (NaTFA-HFIP) using a polystyrene-divinylbenzene packed linear column with a flow rate of $0.5 \mathrm{~mL} \cdot \mathrm{min}^{-1}$. Chromatograms were calibrated against poly(methyl methacrylate) (PMMA) monodisperse standards.

The thermal behavior of polyesters was examined by DSC using a Perkin-Elmer DSC Pyris 1. Thermograms were obtained from 3 to $5 \mathrm{mg}$ samples at heating/cooling rates of $10^{\circ} \mathrm{C} \cdot \mathrm{min}^{-1}$ under a nitrogen flow of $20 \mathrm{~mL} \cdot \mathrm{min}^{-1}$. Indium and zinc were used as standards for temperature and enthalpy calibration, respectively. The glass-transition temperatures were determined at a heating rate of $20{ }^{\circ} \mathrm{C} \cdot \mathrm{min}^{-1}$ from rapidly melt-quenched polymer samples. The treatment of the samples for isothermal crystallization experiments was the following: the thermal history was removed by heating the sample up to $150^{\circ} \mathrm{C}$ and left at this temperature for $5 \mathrm{~min}$, and then it was cooled at $20^{\circ} \mathrm{C} \cdot \mathrm{min}^{-1}$ to the selected crystallization temperature, where it was left to crystallize until saturation. Isothermal crystallization under the same conditions was also carried out in an Olympus BX51 Polarizing Optical Microscope coupled to a THMS LINKAM heating plate and a cooling system LNP (liquid nitrogen pump). Thermogravimetric analyses were performed under a nitrogen flow of $20 \mathrm{~mL} \cdot \mathrm{min}^{-1}$ at a heating rate of $10^{\circ} \mathrm{C} \cdot \mathrm{min}^{-1}$, within a temperature range of 30 to $600{ }^{\circ} \mathrm{C}$, using a Perkin-Elmer TGA 6 equipment. Sample weights of about $10-15 \mathrm{mg}$ were used in these experiments.

Films for mechanical testing and contact angle measurements were prepared with a thickness of $\sim 200 \mu \mathrm{m}$ by casting from a chloroform solution at a concentration of $100 \mathrm{~g} \cdot \mathrm{L}^{-1}$. For evaluating mechanical properties, the films were cut into strips with a width of $3 \mathrm{~mm}$, while the distance between testing marks was $10 \mathrm{~mm}$. The tensile strength, elongation at break, and Young's modulus were measured at a stretching rate of $30 \mathrm{~mm} \cdot \mathrm{min}^{-1}$ on a Zwick $2.5 / \mathrm{TN} 1 \mathrm{~S}$ testing machine coupled with a compressor Dalbe DR 150 , at $23{ }^{\circ} \mathrm{C}$. Contact angles between liquid and polyester film surfaces were measured by means of a Krüss DSA 100 contact angle measuring system. Angle values were registered after 3 min of dropping $15 \mu \mathrm{L}$ of either water or ethylene glycol onto the polyester surface at $23^{\circ} \mathrm{C}$. Scanning electron microscopy (SEM) images were taken with a field-emission JEOL JSM-7001F instrument (JEOL, Japan) from uncoated samples.

Polymer Synthesis. Synthesis of Poly(alkylene 2,3:4,5-di-Omethylene galactarate)s (PE- $n$ Galx). PE- $n$ Galx polyesters were obtained from linear aliphatic $\alpha, \omega$-diols (1,6-hexanediol, 1,8-octanediol, 1,10-decanediol, or 1,12-dodecanediol) and dimethyl 2,3:4,5-di-Omethylene-galactarate.

Procedure A. A mixture of dimethyl 2,3:4,5-di-O-methylene-galactarate and the corresponding diol at a molar ratio of $1 / 1$ was prepared in a round-bottom flask, and several cycles of argon and vacuum were applied. The temperature was raised to $135^{\circ} \mathrm{C}$ for $30 \mathrm{~min}$ with stirring until homogenization of the mixture, and then TBT catalyst $(0.5 \% \mathrm{~mol}$ respect to monomers) was added. Transesterification reactions were carried out under argon at heating at $140{ }^{\circ} \mathrm{C}$ for $4 \mathrm{~h}$ followed by two periods of $1 \mathrm{~h}$ at 150 and $160^{\circ} \mathrm{C}$, respectively. Polycondensation reactions were performed for $2 \mathrm{~h}$ at $175^{\circ} \mathrm{C}$ under vacuum $(0.6-1.3$ mbar). The polymerized mixture was then dissolved in dichloromethane, and the solution was poured dropwise into diethyl ether while stirring. The precipitated solid was filtered, washed with diethyl ether, and dried under vacuum. 
Procedure $B$. The reaction was performed in a three-necked, cylindrical-bottom flask equipped with a mechanical stirrer, a nitrogen inlet, and a vacuum distillation outlet. A 1/1 molar ratio of the diol to dimethyl 2,3:4,5-di-O-methylene-galactarate and dibutyl tin oxide (DBTO) as catalyst $(0.4 \% \mathrm{~mol}$ respect to monomers) were used. The apparatus was vented with nitrogen several times at room temperature to remove the air and avoid oxidation during the polymerization. Transesterification reactions were carried out under a low nitrogen flow for a period of $3 \mathrm{~h}$ at $140{ }^{\circ} \mathrm{C}$. Polycondensation reactions were left to proceed for $5 \mathrm{~h}$ at $140{ }^{\circ} \mathrm{C}$, under a $0.03-0.06 \mathrm{mbar}$ vacuum. Then, the reaction mixture was cooled to room temperature, and the atmospheric pressure was recovered with nitrogen to prevent degradation. Polymers obtained were dissolved in chloroform and precipitated in excess of methanol to remove unreacted monomers and remaining oligomers. Finally, the polymer was collected by filtration, extensively washed with methanol and diethyl ether, and dried under vacuum.

PE-6Galx. IR (film), $v\left(\mathrm{~cm}^{-1}\right): 1734$ (C=O st), 1260 (C-O asym st, ester), 1165 (C-O sym st, ester), 1093 (C-O asym st, acetal), 799 (C-O sym st, acetal), 724 ( $\mathrm{CH}_{2}$ rock). ${ }^{1} \mathrm{H} \mathrm{NMR}\left(300.1 \mathrm{MHz}, \mathrm{CDCl}_{3}\right)$, $\delta(\mathrm{ppm}): 5.25$ and $5.08\left(2 \mathrm{~s}, 4 \mathrm{H}, 2 \mathrm{CH}_{2}\right), 4.61(\mathrm{~m}, 2 \mathrm{H}, 2 \mathrm{CH}), 4.27(\mathrm{~m}$, $2 \mathrm{H}, 2 \mathrm{CH}), 4.20\left(\mathrm{t}, 4 \mathrm{H}, 2 \mathrm{CH}_{2}\right), 1.70\left(\mathrm{~m}, 4 \mathrm{H}, 2 \mathrm{CH}_{2}\right), 1.40(\mathrm{~m}, 4 \mathrm{H}$, $\left.2 \mathrm{CH}_{2}\right) .{ }^{13} \mathrm{C}\left(75.5 \mathrm{MHz}, \mathrm{CDCl}_{3}\right), \delta(\mathrm{ppm}): 170.3(\mathrm{CO}), 96.8,79.0,75.3$, 65.6, 28.4, 25.4. Anal. Calcd for $\mathrm{C}_{14} \mathrm{H}_{20} \mathrm{O}_{8} \cdot 0.25 \mathrm{H}_{2} \mathrm{O}: \mathrm{C}, 52.40 ; \mathrm{H}, 6.37$. Found: C, 52.08; H, 6.44.

PE-8Galx. IR (film), $v\left(\mathrm{~cm}^{-1}\right): 1733$ (C=O st), 1259 (C-O asym st, ester), 1167 (C-O sym st, ester), 1092 (C-O asym st, acetal), 796 (C-O sym st, acetal), 719 ( $\mathrm{CH}_{2}$ rock). ${ }^{1} \mathrm{H} \mathrm{NMR}\left(300.1 \mathrm{MHz}, \mathrm{CDCl}_{3}\right)$, $\delta(\mathrm{ppm}): 5.26$ and $5.08\left(2 \mathrm{~s}, 4 \mathrm{H}, 2 \mathrm{CH}_{2}\right), 4.61(\mathrm{~m}, 2 \mathrm{H}, 2 \mathrm{CH}), 4.28(\mathrm{~m}$, $2 \mathrm{H}, 2 \mathrm{CH}), 4.20\left(\mathrm{t}, 4 \mathrm{H}, 2 \mathrm{CH}_{2}\right), 1.68\left(\mathrm{~m}, 4 \mathrm{H}, 2 \mathrm{CH}_{2}\right), 1.34(\mathrm{~m}, 8 \mathrm{H}$, $\left.4 \mathrm{CH}_{2}\right) .{ }^{13} \mathrm{C}\left(75.5 \mathrm{MHz}, \mathrm{CDCl}_{3}\right), \delta(\mathrm{ppm}): 170.3(\mathrm{CO}), 96.8,79.0,75.2$, 65.8, 29.0, 28.5, 25.7. Anal. Calcd for $\mathrm{C}_{16} \mathrm{H}_{24} \mathrm{O}_{8} \cdot 0.25 \mathrm{H}_{2} \mathrm{O}$ : C, 55.09; $\mathrm{H}$, 7.08. Found: C, 55.08; H, 7.02.

PE-10Galx. IR (film), $v\left(\mathrm{~cm}^{-1}\right): 1734(\mathrm{C}=\mathrm{O}$ st), $1259(\mathrm{C}-\mathrm{O}$ asym st, ester), 1168 (C-O st sym, ester), 1093 (C-O asym st, acetal), 797 (C-O sym st, acetal), 719 ( $\mathrm{CH}_{2}$ rock). ${ }^{1} \mathrm{H} \mathrm{NMR}\left(300.1 \mathrm{MHz}, \mathrm{CDCl}_{3}\right)$, $\delta(\mathrm{ppm}): 5.25$ and $5.07\left(2 \mathrm{~s}, 4 \mathrm{H}, 2 \mathrm{CH}_{2}\right), 4.60(\mathrm{~m}, 2 \mathrm{H}, 2 \mathrm{CH}), 4.28(\mathrm{~m}$, $2 \mathrm{H}, 2 \mathrm{CH}), 4.19\left(\mathrm{t}, 4 \mathrm{H}, 2 \mathrm{CH}_{2}\right), 1.67\left(\mathrm{~m}, 4 \mathrm{H}, 2 \mathrm{CH}_{2}\right), 1.30(\mathrm{~m}, 12 \mathrm{H}$, $\left.6 \mathrm{CH}_{2}\right) .{ }^{13} \mathrm{C}\left(75.5 \mathrm{MHz}, \mathrm{CDCl}_{3}\right), \delta(\mathrm{ppm}): 170.3(\mathrm{CO}), 96.8,79.0,75.2$, 65.9, 29.4, 29.1, 28.5, 25.7. Anal. Calcd for $\mathrm{C}_{18} \mathrm{H}_{28} \mathrm{O}_{8} \cdot 0.25 \mathrm{H}_{2} \mathrm{O}: \mathrm{C}$, 58.05; H, 7.58. Found: C, 57.47; H, 7.47.

PE-12Galx. IR (film), $v\left(\mathrm{~cm}^{-1}\right): 1734(\mathrm{C}=\mathrm{O}$ st), $1259(\mathrm{C}-\mathrm{O}$ asym st, ester), 1168 (C-O sym st, ester), 1095 (C-O asym st, acetal), 801 (C-O sym st, acetal), $719\left(\mathrm{CH}_{2}\right.$ rock $) .{ }^{1} \mathrm{H}$ NMR $\left(300.1 \mathrm{MHz}, \mathrm{CDCl}_{3}\right)$, $\delta(\mathrm{ppm}): 5.25$ and $5.07\left(2 \mathrm{~s}, 4 \mathrm{H}, 2 \mathrm{CH}_{2}\right), 4.60(\mathrm{~m}, 2 \mathrm{H}, 2 \mathrm{CH}), 4.28(\mathrm{~m}$, $2 \mathrm{H}, 2 \mathrm{CH}), 4.19\left(\mathrm{t}, 4 \mathrm{H}, 2 \mathrm{CH}_{2}\right), 1.67\left(\mathrm{~m}, 4 \mathrm{H}, 2 \mathrm{CH}_{2}\right), 1.27(\mathrm{~m}, 16 \mathrm{H}$, $\left.8 \mathrm{CH}_{2}\right) .{ }^{13} \mathrm{C}\left(75.5 \mathrm{MHz}, \mathrm{CDCl}_{3}\right), \delta(\mathrm{ppm}): 170.3(\mathrm{CO}), 96.8,79.0,75.1$, 65.9, 29.5, 29.4, 29.2, 28.5, 25.8. Anal. Calcd for $\mathrm{C}_{20} \mathrm{H}_{32} \mathrm{O}_{8} \cdot 0.25 \mathrm{H}_{2} \mathrm{O}$ : C, 59.32; H, 8.09. Found: C, 58.60; H, 8.07.

Synthesis of Poly(alkylene adipate)s (PE-nAd). Dimethyl adipate and the corresponding aliphatic $\alpha, \omega$-diol (1,6-hexanediol, 1,8octanediol, 1,10-decanediol, or 1,12-dodecanediol) were introduced in a three-necked, cylindrical-bottom flask equipped with a mechanical stirrer, a nitrogen inlet, and a vacuum distillation outlet. A molar excess of $16,11,3$, and $2 \%$ of diol was used for 1,6-hexanediol, 1,8-octanediol, 1,10-decanediol, and 1,12-dodecanediol, respectively. The apparatus was vented with nitrogen several times at room temperature, heated at $180{ }^{\circ} \mathrm{C}$ under stirring until homogeneization of the mixture, and then titanium(IV) butoxide (TBT) catalyst $(0.5 \% \mathrm{~mol}$ respect to dimethyl adipate) was added. Transesterification reactions were carried out under a low nitrogen flow for a period of $3 \mathrm{~h}$ at $180^{\circ} \mathrm{C}$. The temperature was then increased to $200{ }^{\circ} \mathrm{C}$, and polycondensation reactions were performed at this temperature for $3 \mathrm{~h}$, under a $0.03-0.06$ mbar vacuum. After that, the reaction mixture was cooled to room temperature, and atmospheric pressure was recovered with nitrogen to prevent degradation. The solid mass was dissolved in chloroform, and the polymer was precipitated with methanol, collected by filtration, extensively washed with methanol and diethyl ether, and dried under vacuum.

PE-6Ad. IR (film), $v\left(\mathrm{~cm}^{-1}\right): 1724$ (C=O st), 1256 (C-O asym st, ester), 1162 (C-O st sym ester), 733 and 725 ( $\mathrm{CH}_{2}$ rock). ${ }^{1} \mathrm{H}$ NMR (300.1 MHz, $\left.\mathrm{CDCl}_{3}\right), \delta(\mathrm{ppm}): 4.06\left(\mathrm{t}, 4 \mathrm{H}, 2 \mathrm{CH}_{2}\right), 2.32(\mathrm{t}, 4 \mathrm{H}, 2$ $\left.\mathrm{CH}_{2}\right), 1.64\left(\mathrm{~m}, 8 \mathrm{H}, 4 \mathrm{CH}_{2}\right), 1.38\left(\mathrm{~m}, 4 \mathrm{H}, 2 \mathrm{CH}_{2}\right) .{ }^{13} \mathrm{C}(75.5 \mathrm{MHz}$, $\mathrm{CDCl}_{3}$ ), $\delta$ (ppm): 173.4 (CO), 64.3, 33.9, 28.5, 25.6, 24.4. Anal. Calcd for $\mathrm{C}_{12} \mathrm{H}_{20} \mathrm{O}_{4}$ : C, 63.14; $\mathrm{H}, 8.83$. Found: $\mathrm{C}, 62.46 ; \mathrm{H}, 8.84$.

PE-8Ad. IR (film), $v\left(\mathrm{~cm}^{-1}\right): 1721$ (C=O st), 1257 (C-O asym st, ester), 1165 (C-O sym st, ester), 733 and $725\left(\mathrm{CH}_{2}\right.$ rock). ${ }^{1} \mathrm{H}$ NMR $\left(300.1 \mathrm{MHz}, \mathrm{CDCl}_{3}\right), \delta(\mathrm{ppm}): 4.05\left(\mathrm{t}, 4 \mathrm{H}, 2 \mathrm{CH}_{2}\right), 2.32\left(\mathrm{t}, 4 \mathrm{H}, 2 \mathrm{CH}_{2}\right)$, $1.65\left(\mathrm{~m}, 8 \mathrm{H}, 4 \mathrm{CH}_{2}\right), 1.32\left(\mathrm{~m}, 8 \mathrm{H}, 4 \mathrm{CH}_{2}\right) .{ }^{13} \mathrm{C}\left(75.5 \mathrm{MHz}, \mathrm{CDCl}_{3}\right), \delta$ (ppm): 173.4 (CO), 64.5, 33.9, 29.1, 28.6, 25.8, 24.4. Anal. Calcd for $\mathrm{C}_{14} \mathrm{H}_{24} \mathrm{O}_{4}$ : C, 65.60; H, 9.44. Found: C, 65.06; H, 9.55.

PE-10Ad. IR (film), $v\left(\mathrm{~cm}^{-1}\right): 1726(\mathrm{C}=\mathrm{O}$ st), 1257 (C-O asym st, ester), 1164 (C-O sym st, ester), 732 and $723\left(\mathrm{CH}_{2}\right.$ rock). ${ }^{1} \mathrm{H}$ NMR $\left(300.1 \mathrm{MHz}, \mathrm{CDCl}_{3}\right), \delta(\mathrm{ppm}): 4.05\left(\mathrm{t}, 4 \mathrm{H}, 2 \mathrm{CH}_{2}\right), 2.32\left(\mathrm{t}, 4 \mathrm{H}, 2 \mathrm{CH}_{2}\right)$, $1.62\left(\mathrm{~m}, 8 \mathrm{H}, 4 \mathrm{CH}_{2}\right), 1.30\left(\mathrm{~m}, 12 \mathrm{H}, 6 \mathrm{CH}_{2}\right) .{ }^{13} \mathrm{C}\left(75.5 \mathrm{MHz}, \mathrm{CDCl}_{3}\right), \delta$ (ppm): 173.4 (CO), 64.5, 34.0, 29.4, 29.2, 28.6, 25.9, 24.5. Anal. Calcd for $\mathrm{C}_{16} \mathrm{H}_{28} \mathrm{O}_{4}$ : C, 67.57; $\mathrm{H}, 9.92$. Found: $\mathrm{C}, 67.29 ; \mathrm{H}, 9.98$.

PE-12Ad. IR (film), $v\left(\mathrm{~cm}^{-1}\right): 1728$ (C=O st), 1259 (C-O asym st, ester), 1162 (C-O sym st, ester), 733 and $724\left(\mathrm{CH}_{2}\right.$ rock $) .{ }^{1} \mathrm{H}$ NMR $\left(300.1 \mathrm{MHz}, \mathrm{CDCl}_{3}\right), \delta(\mathrm{ppm}): 4.06\left(\mathrm{t}, 4 \mathrm{H}, 2 \mathrm{CH}_{2}\right), 2.32\left(\mathrm{t}, 4 \mathrm{H}, 2 \mathrm{CH}_{2}\right)$, $1.64\left(\mathrm{~m}, 8 \mathrm{H}, 4 \mathrm{CH}_{2}\right), 1.28\left(\mathrm{~m}, 16 \mathrm{H}, 8 \mathrm{CH}_{2}\right) .{ }^{13} \mathrm{C}\left(75.5 \mathrm{MHz}, \mathrm{CDCl}_{3}\right), \delta$ (ppm): 173.4 (CO), 64.5, 34.0, 29.5, 29.4, 29.2, 28.5, 25.9, 24.4. Anal. Calcd for $\mathrm{C}_{18} \mathrm{H}_{32} \mathrm{O}_{4}$ : C, 69.19; H, 10.32. Found: C, 69.22; H, 10.39 .

Hydrolytic and Enzymatic Degradation Procedures. For hydrolytic and enzymatic degradation studies, films of polyesters with a thickness of $\sim 200 \mu \mathrm{m}$ were prepared by casting from a chloroform solution $\left(c=100 \mathrm{~g} \cdot \mathrm{L}^{-1}\right)$. The films were cut into $10 \mathrm{~mm}$ diameter, 20 to $30 \mathrm{mg}$ weight disks and dried under vacuum to a constant weight. For hydrolytic degradation, samples were immersed in vials containing $10 \mathrm{~mL}$ of sodium phosphate buffer $(\mathrm{pH} 7.4)$, sodium carbonate buffer $(\mathrm{pH} 10.5)$ or citric acid buffer $(\mathrm{pH} 2.0)$ at $23^{\circ} \mathrm{C}$. After incubation for the scheduled period of time, the samples were rinsed thoroughly with distilled water and dried to constant weight. The enzymatic degradation was carried out at $37{ }^{\circ} \mathrm{C}$ in vials containing $10 \mathrm{~mL}$ of the enzymatic medium, consisting of a $\mathrm{pH} 7.4$ buffered sodium phosphate solution containing either lipase from porcine pancreas $(10 \mathrm{mg})$ or Amano lipase from Pseudomonas fluorescens $(10 \mathrm{mg})$. The buffered enzyme solution was replaced every $72 \mathrm{~h}$ to maintain the enzyme activity. At the end of the scheduled incubation periods, the disks were withdrawn from the incubation medium, washed thoroughly with distilled water, dried to a constant weight, and analyzed by GPC chromatography and NMR spectroscopy.

\section{RESULTS AND DISCUSSION}

Synthesis and Characterization. The synthesis of polygalactarates (PE- $n \mathrm{Galx})$ and polyadipates (PE- $n \mathrm{Ad})$ studied in this work was carried out by reaction of linear $1, n$-alkanediols with the dimethyl ester of either 2,3:4,5-di-O-methylene-galactaric or adipic acid, respectively. Reactions were invariably performed in the melt and in the total absence of solvents to imitate as far as possible the conditions usually applied in the industrial practice. They were conducted in two successive stages at temperatures between 140 and $200{ }^{\circ} \mathrm{C}$ and under a progressively diminishing reaction pressure to facilitate the removal of released byproducts. For the synthesis of polyadipates, the reaction was carried out at $180-200{ }^{\circ} \mathrm{C}$ using the familiar TBT catalyst and a small excess of diol with regard to the diester to compensate for the loss of volatiles. The resulting PE- $n$ Ad polyesters had $M_{\mathrm{w}}$ between 
38000 and 42000 , with polydispersities close to 2 . When this procedure was applied to the synthesis of polygalactarates, nonsoluble products were invariably obtained, suggesting the occurrence of cross-linking reactions involving the acetal group. It is noteworthy to mention in this regard that opening of the tetrahydrofurane rings of isomannide has been reported to take place in the polycondensation of this compound with terephthalic acid. ${ }^{15}$ To circumvent such undesirable side reactions, some modifications were explored in this work. As a result, two slightly different procedures, which are detailed in Figure 2, leading to linear polyesters with dissimilar molecular weights, were finally applied for obtaining PE- $n$ Galx. In procedure $\mathrm{A}$, polycondensation was carried out within the $140-175^{\circ} \mathrm{C}$ temperature range with TBT catalyst and under a minimum pressure of $0.6 \mathrm{mbar}$; in this case, the resulting polyesters attained relatively small molecular weight polymers, with $M_{\mathrm{w}}$ confined in the $\sim 5000-10000$ interval, and intrinsic viscosities ranging between 0.19 and

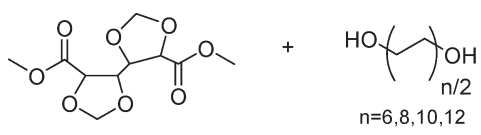

A) LMW

TBT catalyst

1. Transesterification $140-160^{\circ} \mathrm{C}, 6 \mathrm{~h}, 1 \mathrm{~atm}$

2. Polycondensation $175^{\circ} \mathrm{C}, 2 \mathrm{~h}, 0.6-1.3$ mbar

B) $\mathrm{HMW}$

DBTO catalyst

1. Transesterification $140^{\circ} \mathrm{C}, 3 \mathrm{~h}, 1 \mathrm{~atm}$

2. Polycondensation $140^{\circ} \mathrm{C}, 5 \mathrm{~h}, 0.03-0.06 \mathrm{mbar}$

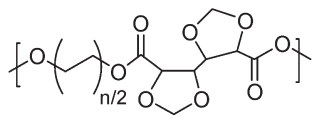

PE- $n$ Galx $n=6,8,10,12$

Figure 2. Polymerization reactions leading to PE- $n$ Galx polyesters.
$0.23 \mathrm{dL} \cdot \mathrm{g}^{-1}$. In procedure $\mathrm{B}$, TBT was replaced by the more active DBTO catalyst, temperature was maintained at $140{ }^{\circ} \mathrm{C}$ along the whole process, and pressure in the second step was lowered down to hundredths of a mbar; under these conditions, PE- $n$ Galx with intrinsic viscosities above $0.5 \mathrm{dL} \cdot \mathrm{g}^{-1}$ and $M_{\mathrm{w}}$ comprised in the $\sim 35000-45000$ range were obtained. The polymer size features of the three sets of polyesters are compared in Table 1. In addition to GPC, the $M_{n}$ of the polyesters were also estimated by end-group analysis carried out by NMR, and an acceptable concordance was found between values provided by the two techniques; with the exception of PE-10Galx obtained by procedure $\mathrm{A}$, the polydispersity of the polyesters in the three series was not far from 2, as it is usually found in linear polycondensates.

The composition of polygalactarates obtained by procedure $B$ as well as of polyadipates was ascertained by combustion analysis. It was noticed that a better correspondence between theoretical and experimental values could be attained if calculations were made assuming that one-fourth of a mol of water per mol of polyester was present in PE- $n$ Galx. This approach is habitually used with carbohydrate-based polycondensates to take into account the high water affinity exhibited by these compounds. ${ }^{24}$ Infrared spectra of PE- $n$ Galx were very similar for the whole series, showing the typical carboxylate $(\sim 1730, \sim 1260$, and $\left.\sim 1170 \mathrm{~cm}^{-1}\right)$ and cyclic acetal $\left(\sim 1090\right.$ and $\left.\sim 800 \mathrm{~cm}^{-1}\right)$ stretching absorptions as well as the methylene stretching (3000-2850 cm $\left.\mathrm{cm}^{-1}\right)$, bending $\left(\sim 1470 \mathrm{~cm}^{-1}\right)$, and rocking $\left(\sim 720 \mathrm{~cm}^{-1}\right)$ bands, with intensities increasing steadily with the value of $n$. The same absorption bands were observed in the infrared spectra recorded from the PE-nAd series but with the logical absence of those arising from the acetal group. The precise wavenumber values observed for each polymer are given in the Experimental Section, and the IR spectra of the three sets of polyesters are provided in the Supporting Information (SI) file linked to this paper. NMR spectroscopy confirmed definitely the chemical structure of PE- $n \mathrm{Galx}$, giving an account of all the groups contained in the repeating unit of every polyester, with signals

Table 1. Molecular weights, solubility and wettability of PE- $n$ Galx and PE- $n$ Ad polyesters

\begin{tabular}{|c|c|c|c|c|c|c|c|c|c|c|c|c|}
\hline \multirow[b]{2}{*}{ polyester } & \multicolumn{5}{|c|}{ molecular weight } & \multicolumn{5}{|c|}{ solubility $^{d}$} & \multicolumn{2}{|c|}{ contact angle $^{e}$} \\
\hline & {$[\eta]^{a}$} & $M_{\mathrm{n}}^{b}$ & $M_{\mathrm{n}}{ }^{c}$ & $M_{\mathrm{w}}{ }^{c}$ & $\mathrm{PD}^{c}$ & $\begin{array}{l}\mathrm{H}_{2} \mathrm{O} \\
\mathrm{EtOH}\end{array}$ & $\begin{array}{c}\mathrm{Et}_{2} \mathrm{O} \\
\mathrm{DMSO}\end{array}$ & $\begin{array}{l}\text { NMP, } \\
\text { DMF }\end{array}$ & $\begin{array}{l}\text { THF, } \\
\mathrm{CHCl}_{3}\end{array}$ & $\begin{array}{c}\text { HFIP, } \\
\text { TFA }\end{array}$ & $\begin{array}{l}\theta_{\text {water }} \\
(\operatorname{deg})\end{array}$ & $\begin{array}{c}\theta_{\mathrm{EG}} \\
(\mathrm{deg})\end{array}$ \\
\hline \multicolumn{13}{|l|}{ LMW } \\
\hline PE-6Galx & 0.19 & 4400 & 2800 & 5100 & 1.8 & - & - & + & + & + & n.d. & n.d. \\
\hline PE-8Galx & 0.22 & 4700 & 3800 & 11100 & 2.9 & - & - & + & + & + & n.d. & n.d. \\
\hline PE-10Galx & 0.22 & 4600 & 2900 & 11400 & 3.9 & - & - & + & + & + & n.d. & n.d. \\
\hline PE-12Galx & 0.23 & 4700 & 3300 & 7300 & 2.2 & - & - & + & + & + & n.d. & n.d. \\
\hline \multicolumn{13}{|l|}{ HMW } \\
\hline PE-6Galx & 0.51 & 16800 & 15100 & 34700 & 2.3 & - & - & + & + & + & 82.4 & 57.6 \\
\hline PE-8Galx & 0.62 & 18000 & 17200 & 43100 & 2.5 & - & - & + & + & + & 84.9 & 56.5 \\
\hline PE-10Galx & 0.53 & 17100 & 15600 & 34900 & 2.2 & - & - & + & + & + & 88.1 & 65.1 \\
\hline PE-12Galx & 0.59 & 16200 & 15200 & 38100 & 2.5 & - & - & + & + & + & 88.6 & 67.1 \\
\hline PE-6Ad & 0.68 & 23800 & 21700 & 42200 & 1.9 & - & - & - & + & + & 102.8 & 73.2 \\
\hline PE-8Ad & 0.59 & 16400 & 15500 & 35300 & 2.3 & - & - & - & + & + & 104.4 & 77.8 \\
\hline PE-10Ad & 0.62 & 18000 & 15700 & 36600 & 2.3 & - & - & - & + & + & 109.6 & 84.3 \\
\hline PE-12Ad & 0.66 & 16000 & 16900 & 38000 & 2.2 & - & - & - & + & + & 112.5 & 75.1 \\
\hline
\end{tabular}

${ }^{a}$ Intrinsic viscosity in $\mathrm{dL} \cdot \mathrm{g}^{-1}$ measured in chloroform at $25^{\circ} \mathrm{C} .{ }^{b}$ Number-average molecular weight in $\mathrm{g} \cdot \mathrm{mol}^{-1}$ determined by ${ }^{1} \mathrm{H}$ NMR end group analysis. ${ }^{c}$ Number and weight-average molecular weights in $\mathrm{g} \cdot \mathrm{mol}^{-1}$ measured by GPC in HFIP against PMMA standards. ${ }^{d}(-)$ Insoluble, $(+)$ soluble.

${ }^{e}$ Static measurement in water and ethylene glycol after 3 min of dropping. n.d: not determined. 


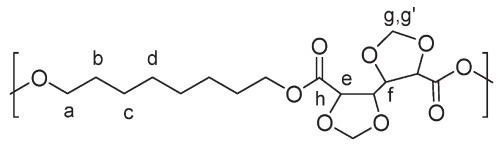

g g'
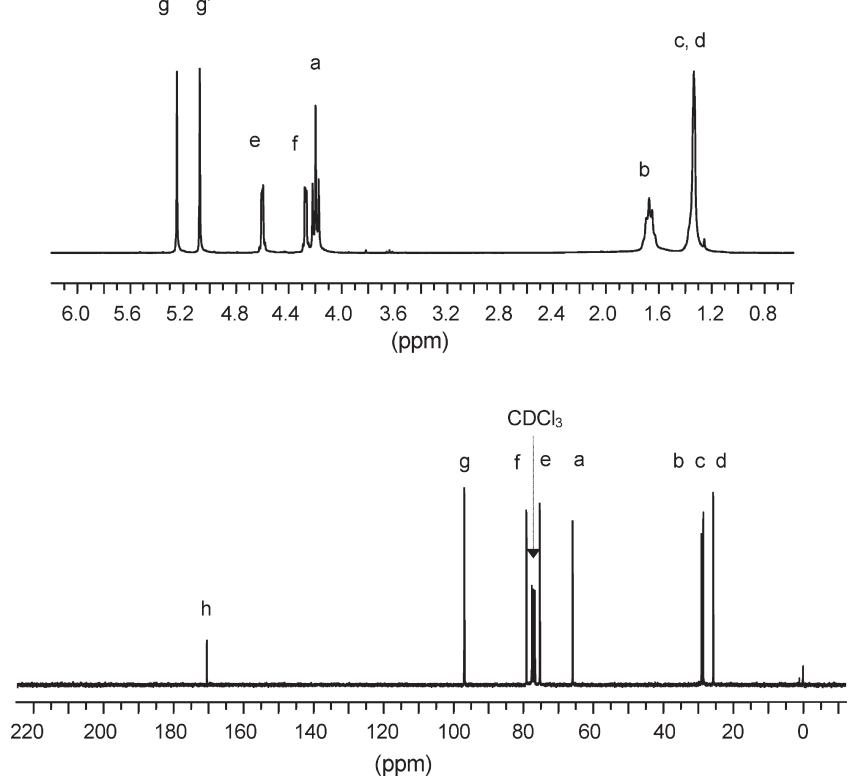

Figure 3. ${ }^{1} \mathrm{H}$ (top) and ${ }^{13} \mathrm{C}$ NMR (bottom) spectra of PE-8Galx (HMW).

exhibiting the expected area and multiplicity, whereas no trace of any other signal was detected in the spectra. A detailed description of the NMR spectra of all PE- $n$ Galx as well as those recorded from PE- $n$ Ad is given in the Experimental Section; for illustration, both ${ }^{1} \mathrm{H}$ and ${ }^{13} \mathrm{C}$ spectra of PE-8Galx are shown in Figure 3.

Due to the absence of strong intermolecular interactions, aliphatic polyesters distinguish among polycondensates by exhibiting a relatively good solubility in organic solvents. The solubility of both PE- $n$ Galx and PE- $n$ Ad was assessed in an assortment of representative solvents, and results are compared in Table 1. Solubility appears to be nonsensitive to the length of the diol polymethylene segment in none of the two series, and the incorporation of the acetalized galactarate unit in the polyester only produces a slight increase in solubility so that PE- $n$ Galx become additionally soluble in NMP and DMF. It is also observed that none of the polyesters becomes water-soluble, although the sugar residue introduces certain hydrophilic character in the polymer chain. This effect was quantitatively evaluated by measuring the wettability of the polyester films by the contact angle technique at short times of contact with water and ethylene glycol as liquids, and results are compared in Table 1. It was found that the contact angle continuously increased with the value of $n$ within each series revealing a progressive decreasing in the polarity of the polymer chain, as expected. Comparison of the two series shows that PE- $n \mathrm{Galx}$ afford much lower angle values than PE- $n$ Ad indicating a larger wettability, as corresponds to the higher polarity provoked by the presence of the diacetalized sugar unit.

Thermal and Mechanical Properties. Galx is a thermally fairly stable solid compound that starts to volatilize above $100{ }^{\circ} \mathrm{C}$ and displays a sublimation temperature of $255{ }^{\circ} \mathrm{C}$ without perceivable decomposition. The thermal stability of polyesters

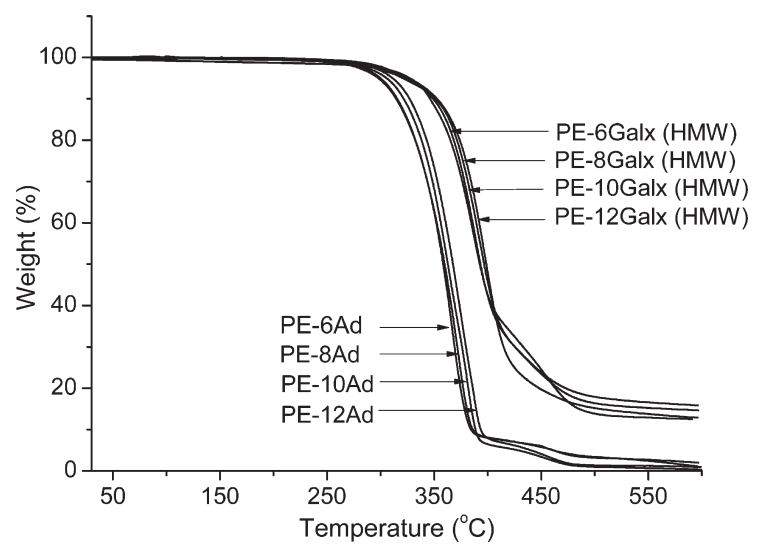

Figure 4. TGA traces of PE- $n$ Galx (HMW) and PE- $n$ Ad.

made from this compound was evaluated by thermogravimetry under inert atmosphere and compared with that displayed by polyadipates. TGA traces obtained for the high molecular weight PE- $n$ Galx and for PE- $n$ Ad are depicted in Figure 4, and thermal data provided by this analysis for the three sets of polyesters under study are presented in Table 2 . The weight loss profiles generated in all cases reveal a thermal degradation mechanism involving one main step occurring at $350-400{ }^{\circ} \mathrm{C}$ and leaving a final residue almost negligible for PE- $n \mathrm{Ad}$, but that amounts to $10-20 \%$ of the initial weight in the case of PE- $n$ Galx. The overview of the collected TGA data leads to the general appreciation that all these polyesters display a more than satisfactory resistance to heat with the onset decomposition temperatures around $300{ }^{\circ} \mathrm{C}$, which is very comparable to the thermal behavior displayed by aliphatic polyesters made from isosorbide. Although there is not a steady correlation of the decomposition temperatures with $n$ in none of the three sets, the ranges of values observed for each of them allow to evaluate comparatively their thermal stability. Thus, there is a clear indication that the resistance to heat of PE- $n$ Galx increases with molecular weight and that the thermal stability of these polyesters is $20-30^{\circ} \mathrm{C}$ higher than that of PE- $n$ Ad having similar $n$ and molecular weight values. The valuable conclusion drawn from this thermogravimetric study is that the insertion of Galx units in aliphatic polyesters instead of reducing their thermal stability contributes to a significant increase in their decomposition temperatures.

Linear aliphatic polyesters without substituents are characterized by displaying low glass transition temperatures. Our DSC $T_{g}$ measurements of PE-nAd polyesters (Table 2) confirm indeed such general observation; these polyesters are so flexible and tend to crystallize so fast that $T_{g}$ could be only determined for the relatively less flexible PE-6Ad which displayed a value as low as $-61^{\circ} \mathrm{C}$. The replacement of the adipate unit by the Galx unit in PE- $n$ Ad increased $T_{\mathrm{g}}$ of PE-6Ad by almost $70^{\circ} \mathrm{C}$ and renders values for the HMW series of PE- $n$ Galx comprised in the -17 to $6{ }^{\circ} \mathrm{C}$ range. It is well-known that the incorporation of rigid structures such as aromatic or aliphatic cyclic units in a polyester chain gives rise to a dramatic increase in $T_{\mathrm{g}}{ }^{26}$ Polyesters with $M_{\mathrm{n}}$ in the $10000-23000 \mathrm{~g} \cdot \mathrm{mol}^{-1}$ range made from isosorbide and aliphatic dicarboxylic acids with lengths similar to the alkanediols used in this work are reported to have $T_{\mathrm{g}}$ between -10 and $10{ }^{\circ} \mathrm{C},{ }^{27}$ which are perfectly comparable to those displayed by HMW PE- $n$ Galx. It seems therefore that Galx exerts a similar effect as Is on $T_{g}$, which is rather striking because a higher stiffness should be expected for the almost planar fused five- 
Table 2. Thermal and Mechanical Properties of PE- $n$ Galx and PE- $n$ Ad Polyesters

\begin{tabular}{|c|c|c|c|c|c|c|c|c|c|c|c|c|c|c|c|c|c|}
\hline \multirow{3}{*}{ polyester } & \multirow{2}{*}{\multicolumn{3}{|c|}{ TGA }} & \multicolumn{11}{|c|}{ DSC } & \multirow{2}{*}{\multicolumn{3}{|c|}{ tensile test ${ }^{h}$}} \\
\hline & & & & \multicolumn{4}{|c|}{ first heating ${ }^{e}$} & \multicolumn{2}{|c|}{ cooling $^{e}$} & \multicolumn{5}{|c|}{ second heating ${ }^{e}$} & & & \\
\hline & $\begin{array}{l}{ }^{\circ} T_{5 \%}{ }^{a} \\
\left({ }^{\circ} \mathrm{C}\right)\end{array}$ & $\begin{array}{c}T_{\mathrm{d}}^{b} \\
\left({ }^{\circ} \mathrm{C}\right)\end{array}$ & $\begin{array}{l}W^{c} \\
(\%)\end{array}$ & $\begin{array}{l}T_{\mathrm{g}}^{d} \\
\left({ }^{\circ} \mathrm{C}\right)\end{array}$ & $T_{\mathrm{m}}\left({ }^{\circ} \mathrm{C}\right)$ & $\begin{array}{c}\Delta H_{\mathrm{m}} \\
\left(\mathrm{J} \cdot \mathrm{g}^{-1}\right)\end{array}$ & $\overline{X_{c}^{g}}$ & $\begin{array}{c}T_{\mathrm{c}} \\
\left({ }^{\circ} \mathrm{C}\right)\end{array}$ & $\begin{array}{c}\Delta H_{\mathrm{c}} \\
\left(\mathrm{J} \cdot \mathrm{g}^{-1}\right)\end{array}$ & $\begin{array}{c}T_{\mathrm{c}} \\
\left({ }^{\circ} \mathrm{C}\right)\end{array}$ & $\begin{array}{c}\Delta H_{\mathrm{c}} \\
\left(\mathrm{J} \cdot \mathrm{g}^{-1}\right)\end{array}$ & $\begin{array}{c}T_{\mathrm{m}} \\
\left({ }^{\circ} \mathrm{C}\right)\end{array}$ & $\begin{array}{c}\Delta H_{\mathrm{m}} \\
\left(\mathrm{J} \cdot \mathrm{g}^{-1}\right)\end{array}$ & $X_{c}^{g}$ & $\begin{array}{c}E \\
(\mathrm{MPa})\end{array}$ & $\begin{array}{c}\sigma \\
(\mathrm{MPa})\end{array}$ & $\begin{array}{c}\varepsilon \\
(\%)\end{array}$ \\
\hline \multicolumn{18}{|l|}{ LMW } \\
\hline PE-6Galx & 280 & 356 & 18 & -4 & $61 / 73^{f}$ & 34.8 & & - & - & - & - & - & - & - & n.d. & n.d. & n.d. \\
\hline PE-8Galx & 315 & 385 & 13 & -17 & $52 / 66 / 74^{f}$ & 44.3 & & - & - & - & - & - & - & - & n.d. & n.d. & n.d. \\
\hline PE-10Galx & 294 & 375 & 12 & -22 & $57 / 75^{f}$ & 48.5 & & - & - & 31 & 30.4 & 78 & 31.8 & - & n.d. & n.d. & n.d. \\
\hline PE-12Galx & 276 & 369 & 10 & -19 & 77 & 42.7 & & 46 & 28.6 & - & - & 79 & 28.2 & - & n.d. & n.d. & n.d. \\
\hline \multicolumn{18}{|l|}{ HMW } \\
\hline PE-6Galx & 325 & 398 & 13 & 6 & $51 / 70 / 73^{f}$ & 15.7 & & - & - & - & - & - & - & - & 154 & 13 & 55 \\
\hline PE-8Galx & 320 & 392 & 15 & -8 & $52 / 69 / 73^{f}$ & 24.5 & & - & - & - & - & - & - & - & 157 & 12 & 50 \\
\hline PE-10Galx & 323 & 387 & 16 & -13 & $53 / 77 / 81^{f}$ & 25.0 & & - & - & 40 & 20.1 & 81 & 20.2 & - & 151 & 13 & 60 \\
\hline PE-12Galx & 327 & 387 & 13 & -17 & 86 & 28.9 & & 35 & 26.3 & - & - & 86 & 26.9 & - & 153 & 13 & 60 \\
\hline PE-6Ad & 300 & 367 & 1 & -61 & 56 & 100.5 & 0.60 & 40 & 69.8 & - & - & 57 & 73.1 & 0.44 & 100 & 7 & 201 \\
\hline PE-8Ad & 297 & 372 & 2 & n.d. & 67 & 108.4 & 0.68 & 46 & 84.6 & - & - & 68 & 85.3 & 0.53 & 88 & 8 & 210 \\
\hline PE-10Ad & 305 & 363 & 1 & n.d. & 73 & 109.2 & 0.70 & 58 & 99.2 & - & - & 74 & 99.7 & 0.64 & 95 & 7 & 203 \\
\hline PE-12Ad & 311 & 375 & 1 & n.d. & 75 & 118.8 & 0.71 & 63 & 102.5 & - & - & 75 & 109.1 & 0.65 & 87 & 6 & 215 \\
\hline
\end{tabular}

${ }^{a}$ Temperature at which $5 \%$ weight loss was observed. ${ }^{b}$ Temperature for maximum degradation rate. ${ }^{c}$ Remaining weight at $600{ }^{\circ} \mathrm{C} .{ }^{d}$ Glass-transition temperature taken as the inflection point of the heating DSC traces of melt-quenched samples recorded at $20{ }^{\circ} \mathrm{C} \cdot \mathrm{min}{ }^{-1}$. ${ }^{e} \mathrm{Melting}\left(T_{\mathrm{m}}\right)$ and crystallization $\left(T_{\mathrm{c}}\right)$ temperatures, and melting $\left(\Delta H_{\mathrm{m}}\right)$ and crystallization $\left(\Delta H_{\mathrm{c}}\right)$ enthalpies measured by DSC at heating/cooling rates of $10^{\circ} \mathrm{C} \cdot \mathrm{min}^{-1}$. ${ }^{f}$ Multiple melting peak. ${ }^{g}$ Crystallinity index based on $100 \%$ crystalline polyester: $\Delta H_{\mathrm{m}}{ }^{\circ} \mathrm{PE}-6 \mathrm{Ad}=38.1 \mathrm{KJ} \cdot \mathrm{mol}^{-1} ; \Delta H_{\mathrm{m}}^{\circ} \mathrm{PE}-8 \mathrm{Ad}=41.0 \mathrm{KJ} \cdot \mathrm{mol}{ }^{-1}$;

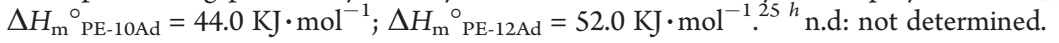

membered tetrahydrofurane rings than for the puckered and conformationally interconvertible 5,5' -bis(1,3-dioxolane) structure. It seems that the relatively elongated shape of Galx will allow a closer packing of the polymer chains, which implies less free volume and accordingly a higher $T_{\mathrm{g}}$. With regard to the influence of the constitution of PE- $n \mathrm{Galx}$ on $T_{\mathrm{g}}$, the effects observed were those according to expectations; $T_{\mathrm{g}}$ of the LMW set were around $10{ }^{\circ} \mathrm{C}$ lower than of the HMW set, and within each set, it decreased almost steadily with increasing values of $n$.

The melting-crystallization behavior of the polyesters was characterized by DSC and the collected data are gathered in Table 2. PE- $n$ Ad polyesters are highly crystalline polymers displaying melting temperatures between 56 and $75{ }^{\circ} \mathrm{C}$ and melting enthalpies greater than $100 \mathrm{~J} \cdot \mathrm{g}^{-1}$ which correspond to crystallinity indexes of $0.6-0.7$, both parameters increasing steadily with the value of $n$. These unsubstituted polyesters crystallized very fast when cooled from the melt with a recovery of about $70-90 \%$ of their initial crystallinity and almost exact replication of their melting temperatures. PE- $n \mathrm{Galx}$ are also crystalline but they show remarkable differences compared to PE- $n$ Ad that evidence the detrimental influence exerted by the diacetalized galactarate residue on crystallinity and crystallizability. The heating DSC traces of PE- $n$ Galx (HMW) are depicted in Figure 5. Those obtained from samples coming directly from synthesis (Figure 5a) displayed wide endotherms consisting of several melting peaks indicative of a defective crystallization of the polyester. Traces with similar profiles were obtained from PE- $n$ Galx (LMW), which are not shown here but that can be inspected on the SI file linked to this paper. Annealing of pristine samples of PE- $n$ Galx (HMW) at temperatures between 60 and $75{ }^{\circ} \mathrm{C}$ for $12 \mathrm{~h}$ homogenized the crystalline morphology; in fact, melting of the annealed polymer took place sharply and at high temperatures, as corresponds to a single population of crystallites of well-defined size (Figure $5 \mathrm{~b}$ ). $T_{m}$ of PE- $n$ Galx (measured on annealed samples) are within the $70-85{ }^{\circ} \mathrm{C}$ range, which is not far from the PE- $n$ Ad melting temperature range, with values increasing regularly with the value of $n$. Whereas neither molecular weight nor constitution seem to notably affect melting temperatures, their influence on melting enthalpy appears to be very remarkable. As can be seen in Table $2, \Delta H_{\mathrm{m}}$ of PE- $n$ Galx (HMW) polymers are several times smaller than those of PE- $n$ Ad and approximately half of the values observed for PE- $n$ Galx (LMW). Lastly, just to note that, with regard to polyesters made from isosorbide reported in the literature, ${ }^{28}$ melting of PE- $n$ Galx takes place at higher temperatures but with similar associated enthalpies.

At a difference with PE- $n$ Ad, PE- $n$ Galx are in general unable to crystallize from the melt. In fact, only PE-12Galx, both LMW and HMW, which is the highest flexible PE- $n$ Galx, showed exothermal crystallization peaks at the cooling DSC traces; the crystallized polymers display similar $T_{\mathrm{m}}$ but significantly lower $\Delta H_{\mathrm{m}}$ than their respective pristine samples. Given the extreme relevance of this property regarding polymer processing, the isothermal crystallization of LMW and HMW PE-12Galx was kinetically analyzed at different temperatures by using the Avrami approach to appraise quantitatively the effect of molecular weight on crystallizability. The relative crystallinity versus time plot as well as the double logarithmic plot for both low and high molecular weight PE-12Galx are compared in Figure 6, and kinetics data extracted from these results are gathered in Table 3. The conclusions that may be drawn from the kinetics study are according to expectations. LMW PE-12Galx crystallized much 

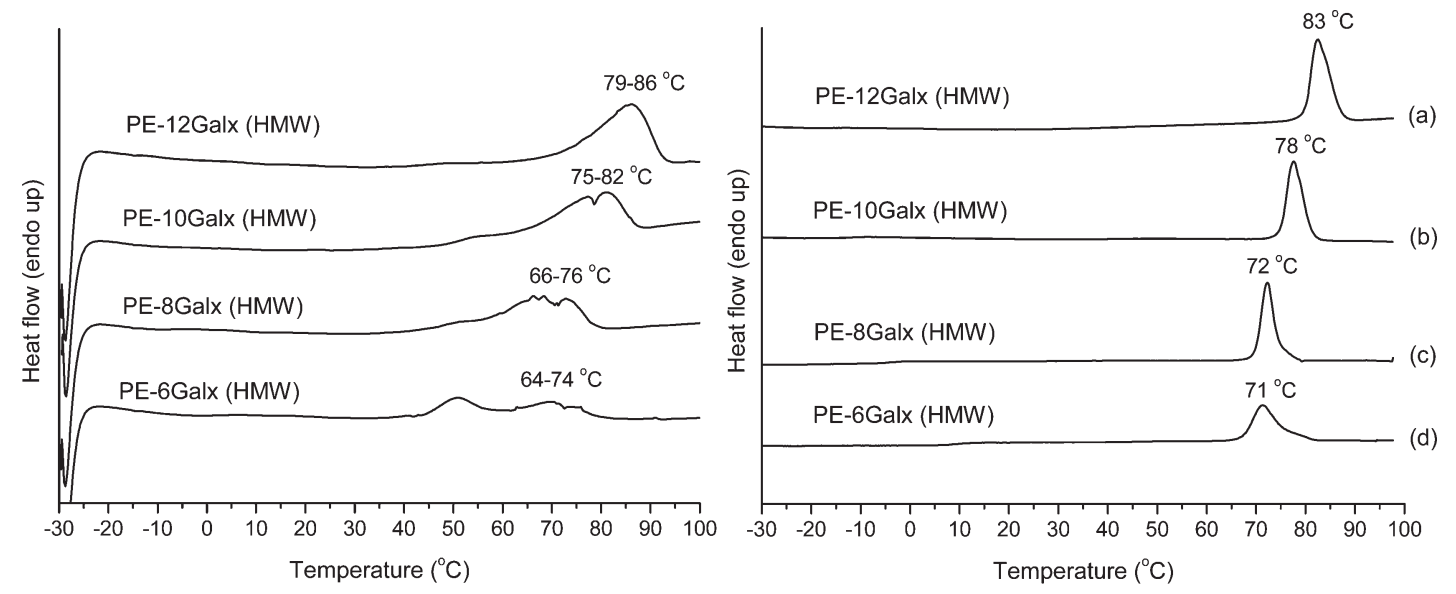

Figure 5. DSC melting traces of samples of PE- $n$ Galx (HMW) coming directly from synthesis (left) and annealed (right) at (a) $75^{\circ} \mathrm{C}$ for $12 \mathrm{~h}$, (b) $70{ }^{\circ} \mathrm{C}$ for $12 \mathrm{~h},(\mathrm{c}) 65^{\circ} \mathrm{C}$ for $12 \mathrm{~h}$, and (d) $60^{\circ} \mathrm{C}$ for $12 \mathrm{~h}$.
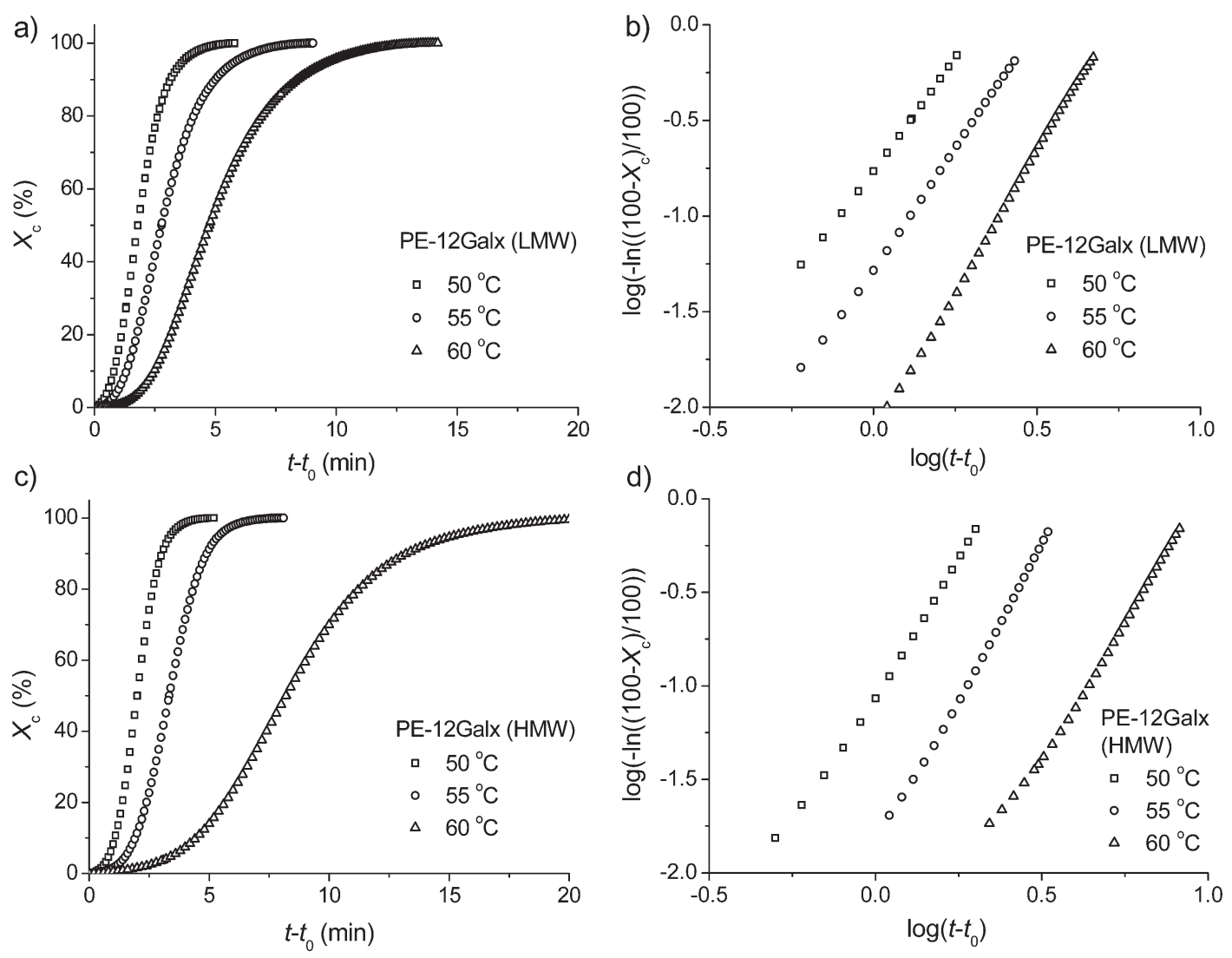

Figure 6. Isothermal crystallization of PE-12Galx at the indicated temperatures. (a) Relative crystallinity vs time plot for PE-12Galx (LMW). (b) Log-log plot for PE-12Galx (LMW). (c) Relative crystallinity vs time plot for PE-12Galx (HMW). (d) Log-log plot for PE-12Galx (HMW).

faster than HMW PE-12Galx, and in both cases crystallization rate diminished as temperature increased revealing that within the studied temperature range, the process is dominated by nucleating effects. Furthermore, the influence of temperature on crystallization rate is more pronounced in the case of high molecular weight PE-12Galx.

A preliminary evaluation of the mechanical behavior of PE- $n$ Galx (HMW) compared to PE- $n$ Ad was made by tensile testing at room temperature. The obtained stress-strain curves are depicted in Figure 7, and the mechanical parameters extracted from them are listed in Table 2. The elastic modulus values of PE- $n$ Galx oscillate in the $150-160 \mathrm{MPa}$ range, whereas PE- $n$ Ad have moduli in the $85-100 \mathrm{MPa}$ range. Tensile strengths reach values of $12-13 \mathrm{MPa}$ and $6-8 \mathrm{MPa}$ for PE- $n \mathrm{Galx}$ and PE- $n \mathrm{Ad}$, respectively, whereas elongations at break are around 50 and $200 \%$. The higher rigidity and lower ductility observed for PE- $n$ Galx seem to be the logical consequence of the higher $T_{\mathrm{g}}$ displayed by these polyesters compared to PE- $n$ Ad, which 
Table 3. Isothermal Crystallization Data for LMW and HMW PE-12Galx

\begin{tabular}{ccccccc} 
polyester & $T_{\mathrm{c}}\left({ }^{\circ} \mathrm{C}\right)$ & $(\mathrm{min})$ & $\begin{array}{c}t_{1 / 2} \\
(\mathrm{~min})\end{array}$ & $n$ & $-\log k$ & $T_{\mathrm{m}}\left({ }^{\circ} \mathrm{C}\right)$ \\
\hline PE-12Galx (LMW) & 50 & 0.28 & 2.08 & 2.28 & 0.75 & 78.2 \\
& 55 & 0.38 & 3.16 & 2.51 & 1.27 & 78.5 \\
PE-12Galx (HMW) & 60 & 0.41 & 5.16 & 2.96 & 2.14 & 79.2 \\
& 50 & 0.35 & 2.36 & 2.80 & 1.04 & 81.9 \\
& 55 & 0.40 & 3.74 & 2.92 & 1.76 & 82.5 \\
& 60 & 0.45 & 8.66 & 2.99 & 2.90 & 83.1 \\
\hline
\end{tabular}

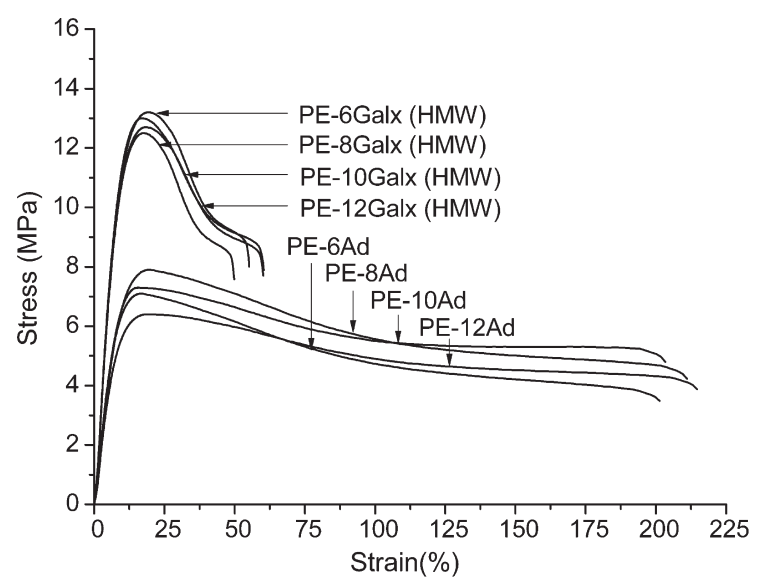

Figure 7. Stress-strain curves for PE- $n$ Galx (HMW) and PE- $n$ Ad.

doubtless is due to the presence of the bicyclic acetal structure in the polymer chain. However, no correlation between the mechanical parameters and the length of polymethylene segment becomes apparent, with the small observed differences falling within the acceptable experimental error limit.

Hydrolytic Degradation and Biodegradation. It is wellknown that polycondensates of synthetic origin are resistant to hydrolysis or even apparently inert for long time intervals when incubated under physiological conditions. It has been repeatedly shown that the incorporation of sugar residues in polyesters, polyamides, or polyurethanes enhances the susceptibility of the polymer to hydrolysis. ${ }^{29-31}$ Both aliphatic and aromatic polyesters containing isosorbide were reported to be hydrolyzed at higher rates than their unsubstituted analogous when incubated under similar conditions. Okada et al. focused on the biodegradability of polyesters made from aliphatic dicarboxylic acids and $1,4: 3,6$ dianhydrohexitols, ${ }^{32-34}$ and concluded that all of them were biodegraded to an extent that largely depended on the configuration of the anhydroalditol. To evaluate the effect of Galx on the hydrolysis of aliphatic polyesters, a comparative study using PE-8Ad and PE-8Galx was carried out in this work. Samples of the two polymers were incubated in aqueous buffers at $\mathrm{pH} 2.0,7.4$, and 10.5 at room temperature for 2 months, and the evolution of the degradation process was followed by measuring the weight loss and the molecular weight of the residual polymer. The results of this comparative study are presented in Figure 8. The profiles obtained for PE-8Ad indicate that there is no loss of mass and that the decrease in molecular weight is practically negligible at any $\mathrm{pH}$ (Figure 8a,c). On the contrary, PE-8Galx showed an appreciable weight
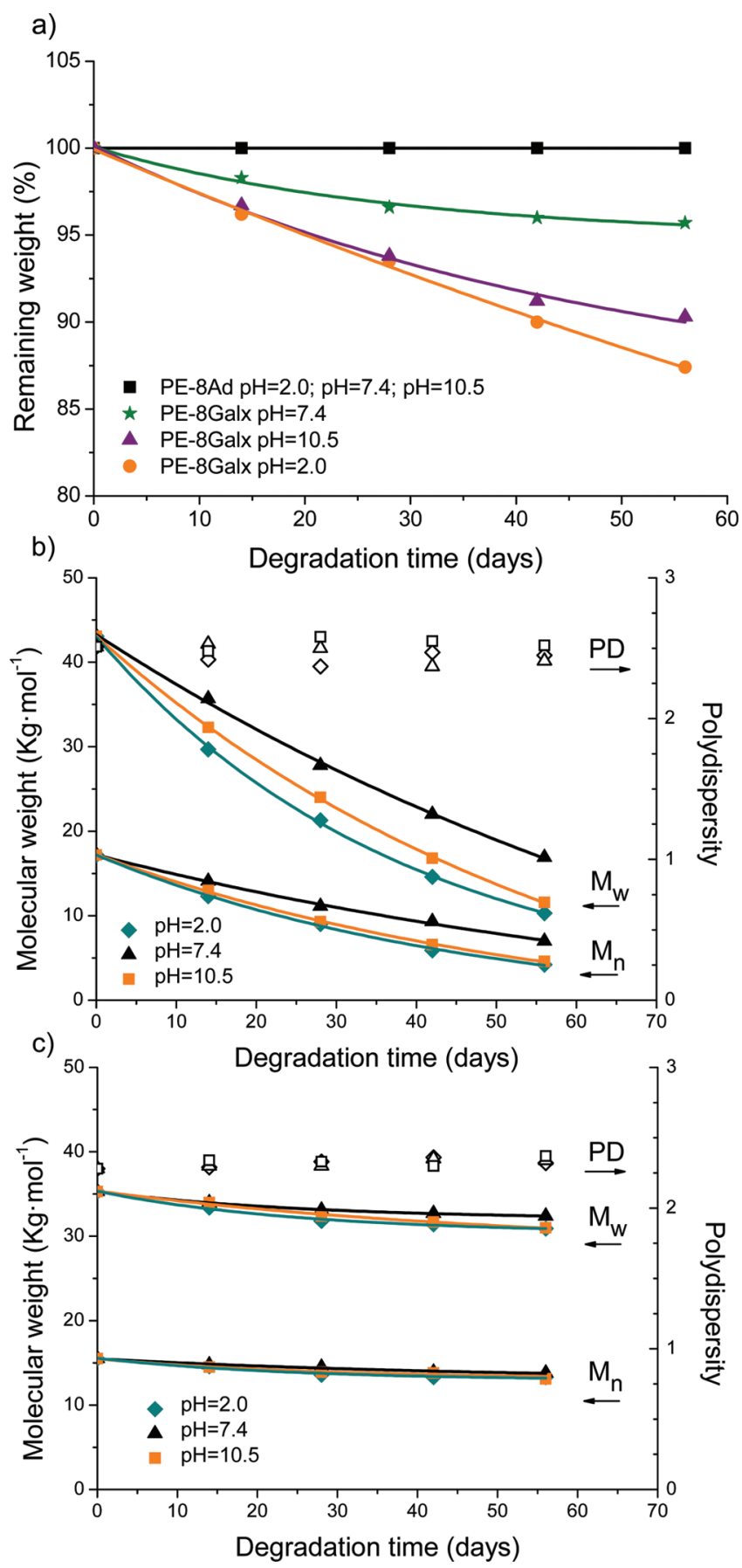

Figure 8. (a) Remaining weight vs hydrolytic degradation time for PE8Galx (HMW) and PE-8Ad at pH 2.0, 7.4, and 10.5. (b) Changes in $M_{\mathrm{w}}$ and $M_{\mathrm{n}}$ (solid symbols) and polydispersity index (empty symbols) vs incubation time for PE-8Galx. (c) Changes in $M_{\mathrm{w}}$ and $M_{\mathrm{n}}$ (solid symbols) and polydispersity index (empty symbols) vs incubation time for PE-8Ad.

loss that was minimum $(\sim 4 \%)$ at $\mathrm{pH} 7.4$ and maximum $(\sim 15 \%)$ at $\mathrm{pH} 2.0$, as well as a significant decreasing of both $M_{\mathrm{w}}$ and $M_{\mathrm{n}}$, whereas polydispersity remained almost constant (Figure 8a,b).

A similar study was then performed with PE-8Ad and PE$8 \mathrm{Galx}$ but adding either $P$. fluorescens or porcine pancreas lipases to the incubation medium at $\mathrm{pH} 7.4$, and results obtained over an 

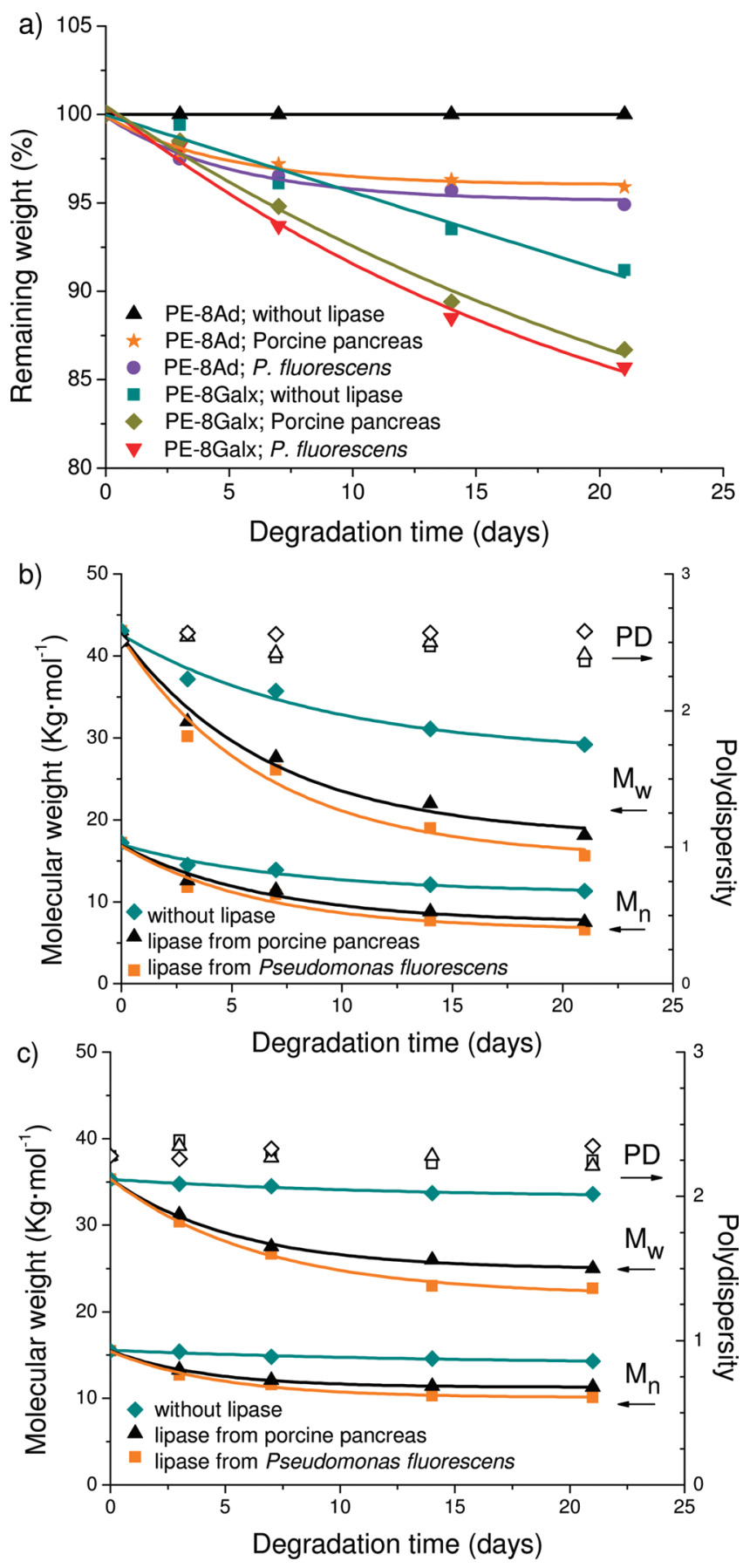

Figure 9. Degradation of PE-8Galx (HMW) and PE-8Ad in the presence of lipases from Pseudomonas fluorescens and porcine pancreas, and without lipase. (a) Remaining weight vs degradation time. (b) Changes in $M_{\mathrm{w}}$ and $M_{\mathrm{n}}$ (solid symbols) and polydispersity index (empty symbols) vs incubation time for PE-8Galx. (c) Changes in $M_{\mathrm{w}}$ and $M_{\mathrm{n}}$ (solid symbols) and polydispersity index (empty symbols) vs incubation time for PE-8Ad.

incubation period of three weeks at $37{ }^{\circ} \mathrm{C}$ are presented in Figure 9. In the presence of lipases, both PE-8Ad and PE-8Galx showed appreciable greater weight losses and molecular weight reductions than in the absence of enzymes indicating that the hydrolysis of both polyesters was speeded by lipases. The activity of the two lipases was not noteworthy different as neither was the sensitivity of the two polymers to the enzymatic action; in fact, a comparison of the plots in Figure 9 clearly reveals that the greater degree of biodegradation apparently observed for PE$8 \mathrm{Galx}$ is the only consequence of its lower intrinsic stability against hydrolysis.

The changes taking place in the micromorphology of PE-8Ad and PE-8Galx due to the degradation process were revealed by SEM analysis as it is illustrated in Figure 10. The surface of a fresh fractured pristine sample of PE-8Ad exhibited a spherulitic texture, which became more vivid after incubation in water at $\mathrm{pH} 2.0$, probably due to the removal of some intra- and interspherulitic amorphous material. Upon incubation in the presence of porcine pancreas lipase, the surface became smoother and developed some small cracks, indicating that a certain degradation in bulk happened. The results obtained in the parallel analysis carried out on PE-8Galx were clearly different. In this case, the initial surface did not display any feature of crystalline morphology, and after incubation in acidic water, plenty of holes and grooves appeared delineating what seems to be a texture made of relatively small impinging spherulites. In the presence of lipase, large cracks causing the total fracture of the material became apparent. The SEM pictures support the conclusion that PE-8Galx becomes more severely degraded than PE$8 \mathrm{Ad}$, both in the presence and in the absence of lipases, and that the degradation process does not follow the same mechanism in each case.

Finally, a NMR study was made to explore how the polyester chain is degraded at the molecular level. The changes taking place in the ${ }^{1} \mathrm{H}$ NMR spectrum of a sample of PE-8Galx upon incubation in aqueous buffer at $\mathrm{pH} 2.0$ are shown in Figure 11. All the signals present in the original spectrum remained unaltered after degradation, and the only changes observed after incubation was the appearing of a small signal corresponding to hydroxymetyl group at $3.6 \mathrm{ppm}$. ${ }^{1} \mathrm{NMR}$ spectra of PE-8Galx samples incubated at $\mathrm{pH} 7.4$ and 10.5 afforded similar results, indicating that degradation proceeded by splitting of the relatively weak ester group without modification of the polymer chain structure. The result is rather striking because the acetal group is known to be sensitive to acidic conditions ${ }^{35}$ and the opening of the dioxolane rings should have therefore been expected to happen to some extent. To check the stability of the diacetal structure, dimethyl 2,3:4,5-di-O-methylene-galactarate was incubated at room temperature in aqueous buffer at $\mathrm{pH}$ 2.0, 7.4, and 10.5. The initial powdered nonsoluble sample dissolved as degradation proceeded, and the NMR analysis of the solution after three months revealed that hydrolysis of the ester groups had happened almost quantitatively at both $\mathrm{pH} 2.0$ and 10.5 , whereas at $\mathrm{pH} 7.4$ about $5 \%$ of the initial diester was still remaining. What was really remarkable is that the acetal group stayed intact after the treatment with whatever were the incubation conditions. The ${ }^{1} \mathrm{H}$ NMR spectrum of the incubating medium at $\mathrm{pH} 2.0$ is depicted in Figure 12, showing all the expected signals due to the protons of the dioxolane ring with their right relative areas. It is concluded therefore that the methylene diacetal of the galactaric unit is extremely resistant to hydrolysis. This result dissipates possible concerns about instability of PE- $n$ Galx due to uncontrolled opening of the acetal rings and allows to anticipate a satisfactory behavior of these polyesters in processing and handling. 

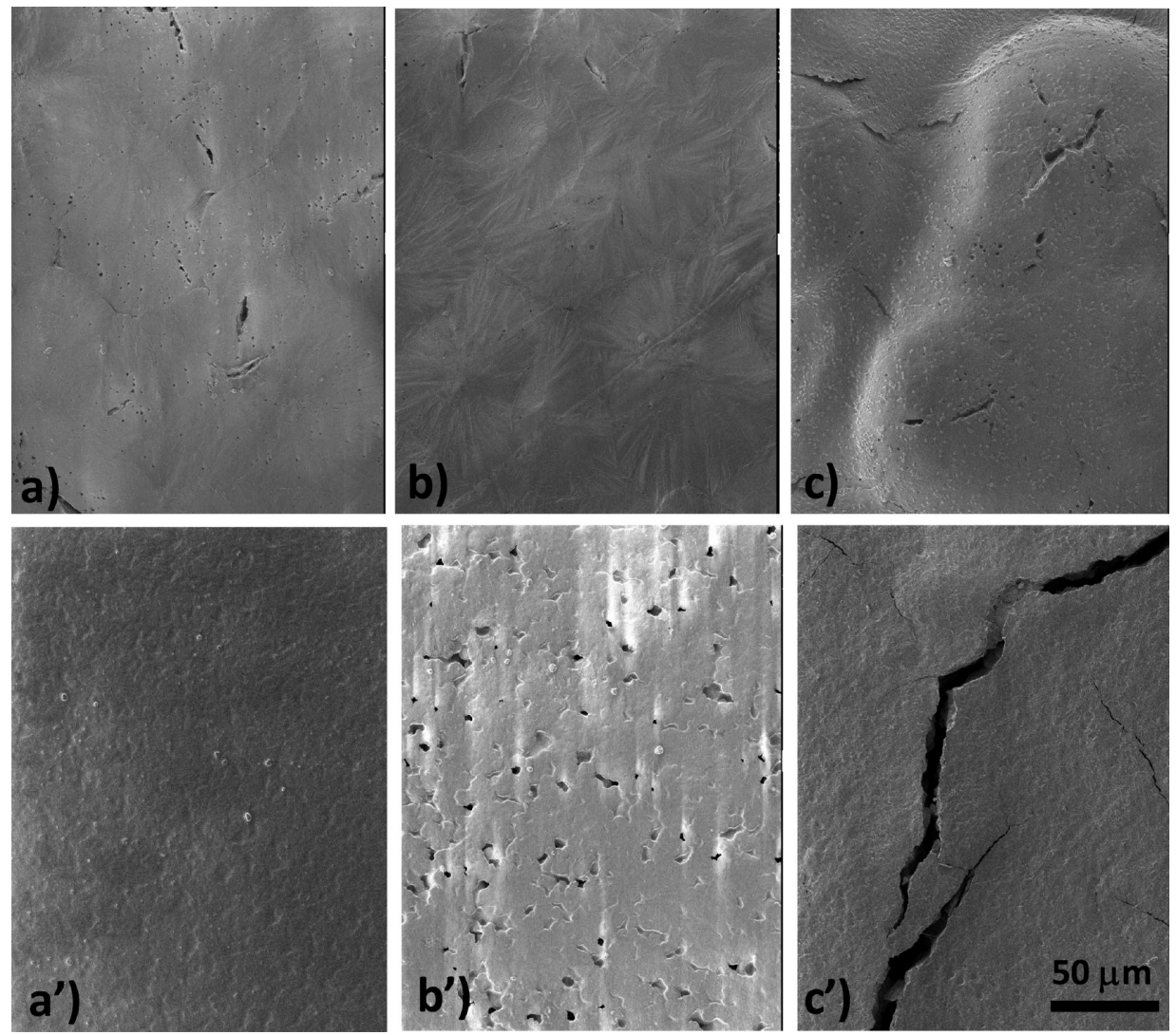

Figure 10. SEM micrographs of PE-8Ad (top) and PE-8Galx (HMW; bottom): (a, $\left.\mathrm{a}^{\prime}\right)$ Initial sample; (b, $\left.\mathrm{b}^{\prime}\right)$ After incubation at $\mathrm{pH}=2.0$ for 56 days; $\left(c, c^{\prime}\right)$ After incubation in the presence of lipase from porcine pancreas at $\mathrm{pH}=7.4$ for 21 days.<smiles>CCOC(=O)C1O[C@H](C)OC1C1OCO[C@H]1C(=O)OCCCCCCCCOC(C)C</smiles>
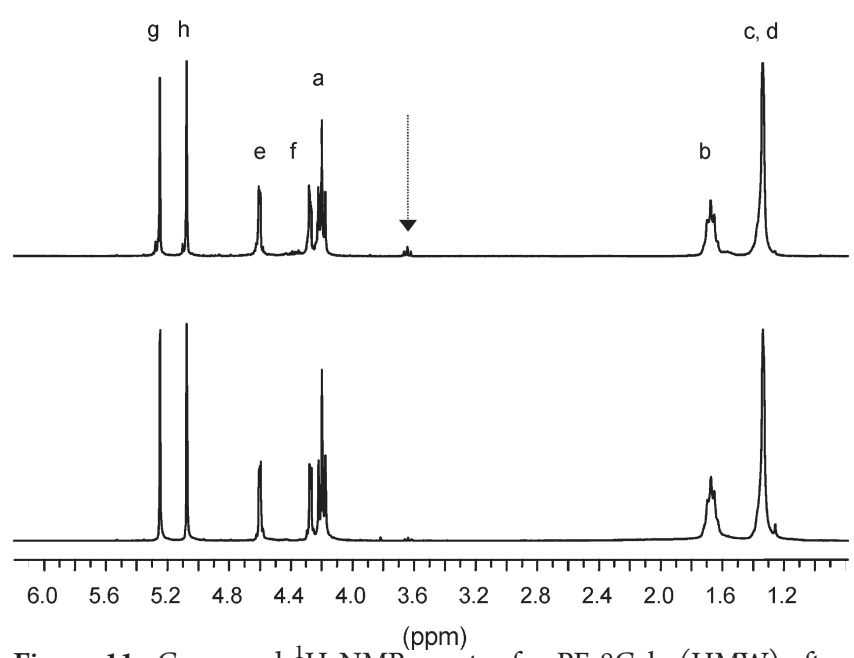

Figure 11. Compared ${ }^{1} \mathrm{H}$ NMR spectra for PE-8Galx (HMW) after incubation at $\mathrm{pH}=2.0$ for 56 days (top) and initial sample (bottom). The arrow indicates the signal arising from $-\mathrm{CH}_{2} \mathrm{OH}$ end groups that appear upon hydrolysis of the main chain ester group.

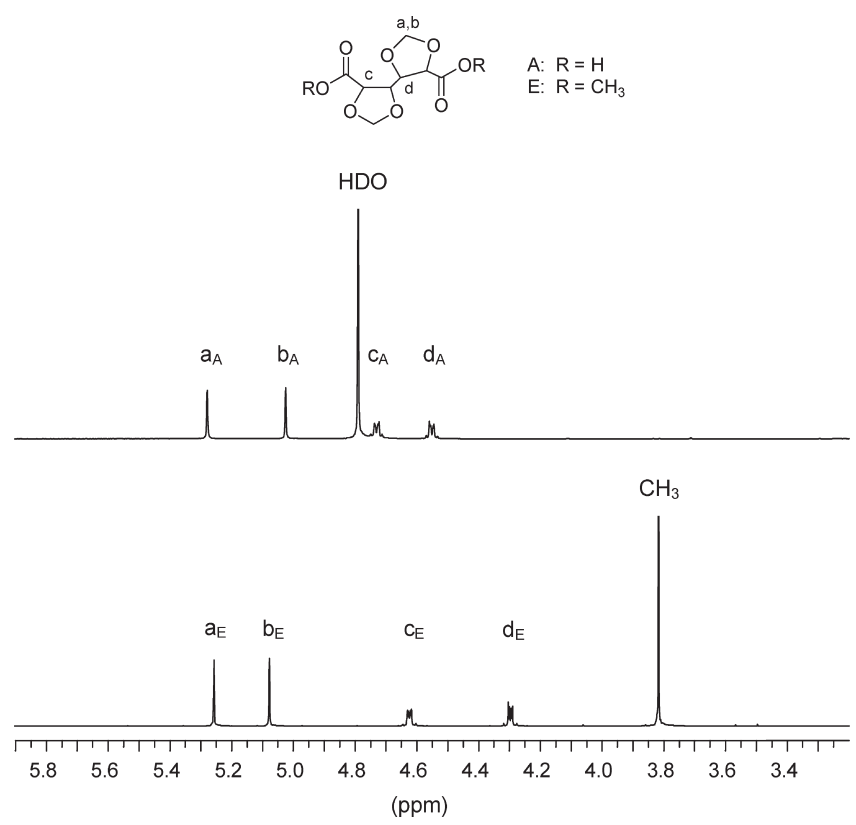

Figure 12. ${ }^{1} \mathrm{H}$ NMR spectra in $\mathrm{D}_{2} \mathrm{O}$ of the product resulting after incubation of dimethyl 2,3:4,5-di-O-methylene galactarate at $\mathrm{pH} 2.0$ for three months at room temperature (top) and of initial sample in $\mathrm{CDCl}_{3}$ (bottom).

\section{CONCLUSIONS}

The bicyclic acetalized dimethyl 2,3:4,5-di-O-methylene-galactarate compound was successfully used as monomer for the 
synthesis of linear polyesters $\mathrm{PE}-n \mathrm{Galx}$ by polycondensation in the melt with alkanediols. The use of DBTO instead of TBT as catalyst allowed to proceed at lower temperature without increasing reaction times, which led to attaining higher molecular weights. PE- $n$ Galx displayed solubility similar to their homologous linear nonsubstituted polyesters PE- $n \mathrm{Ad}$, but they were more hydrophilic. The presence of the diacetal unit in the polyester slightly improved the thermal stability, increased notably $T_{\mathrm{g}}$, increased slightly $T_{\mathrm{m}}$, and repressed partially the crystallizability of the polyesters. Due to their higher $T_{g}, P E-$ $n$ Galx appeared to be stiffer and less ductile than PE- $n$ Ad. The polyesters containing Galx units were degraded by water through splitting of the ester group, whereas the acetal group remained stable against hydrolysis. Hydrolysis of PE- $n$ Galx took place at a higher rate than for PE- $n \mathrm{Ad}$, and in both cases, degradation was accelerated by enzymes with a similar effect.

\section{ASSOCIATED CONTENT}

S Supporting Information. Comparison of FTIR spectra of PE- $n$ Galx and PE- $n$ Ad. DSC traces of LMW PE- $n$ Galx. Comparison of TGA thermograms of LMW and HMW PE$n$ Galx. SEM micrographs of PE-8Galx and PE-8Ad after degradation. This material is available free of charge via the Internet at http://pubs.acs.org.

\section{AUTHOR INFORMATION}

\section{Corresponding Author}

*E-mail: sebastian.munoz@upc.edu.

\section{ACKNOWLEDGMENT}

Financial support for this work was provided by MICINN (Spain) with Grant MAT2009-14053-C02. Authors are also indebted to MEC (Spain) for the FPU grant awarded to C.L.

\section{REFERENCES}

(1) Wool, R.; Sun, S. Biobased Polymers and Composites; Academic Press: New York, 2005.

(2) Wang, Q.; Dordick, J. S.; Linhardt, R. J. Chem. Mater. 2002, 14, 3232-3244.

(3) Bou, J.; Rodríguez-Galán, A.; Muñoz-Guerra, S. Biodegradable optically active polyamides. In The Polymeric Materials Encyclopedia; Salomone, Ed.; CRC Press: Boca Raton, FL, 1996; Vol 1, p 561

(4) Kricheldorf, H. R. J. Macromol. Sci. 1997, C37, 599-631.

(5) Galbis, J. A.; García-Martín, M. G. In Monomers, Polymers and Composites from Renewable Resources; Belgacem, M. N., Gandini, A., Eds.; Elselvier: Oxford, U.K., 2008; pp 89-114.

(6) García-Martín, M. G.; Pérez, R. R.; Hernández, E. B.; Espartero, J. L.; Muñoz-Guerra, S.; Galbis, J. A. Macromolecules 2005, $38,8664-8670$.

(7) Hadier, A. F.; Williams, C. K. J. Polym. Sci., Polym. Chem. 2008, 46, 2891-2896.

(8) Fenouillot, F.; Rousseau, A.; Colomines, G.; Saint-Loup, R.; Pascault, J.-P. Prog. Polym. Sci. 2010, 35, 578-622.

(9) Galbis, J. A.; García-Martín, M. G. Chem. Curr. Top. 2010, 295, 147-176.

(10) Caouthar, A.; Roger, P.; Tessier, M.; Chatti, S.; Blais, J. C.; Bortolussi, M. Eur. Polym. J. 2007, 43, 220-230.

(11) Chatti, S.; Schwarz, G.; Kricheldorf, H. R. Macromolecules 2006, 39, 9064-9070.

(12) Marín, R.; Muñoz-Guerra, S. J. Appl. Polym. Sci. 2009, 114, 3723-3736.
(13) Sablong, R.; Duchateau, R.; Koning, C. E.; de Wit, G.; van Es, D.; Koelewijn, R.; van Haveren, J. Biomacromolecules 2008, 9, 3090-3097.

(14) Noordover, B. A. J.; van Staalduinen, V. G.; Duchateau, R.; Koning, C. E.; van Benthem, R. A. T. M.; Mak, M.; Heise, A.; Frissen, A. E.; van Haveren, J. Biomacromolecules 2008, 7, 3406-3416.

(15) Thiem, J.; Lüders, H. Polym. Bull. 1984, 11, 365-369.

(16) Storbeck, R.; Rehahn, M.; Balluff, M. Makromol. Chem. 1993, 194, 53-64.

(17) Quintana, R.; Martínez de Ilarduya, A.; Alla, A.; Muñoz-Guerra, S. J. Polym. Sci., Polym. Chem 2011, 49, 2252-2260.

(18) Butler, K.; Lawrance, D. R.; Stacey, M. J. Chem. Soc. 1958, 740-743.

(19) Rodríguez Galán, A.; Bou, J. J.; Muñoz-Guerra, S. J. Polym. Sci., Polym. Chem. 1992, 30, 713-721.

(20) Iribarren, J. I.; Martínez de Ilarduya, A.; Alemán, C.; Oraison, J. M.; Rodríguez-Galán, A.; Muñoz-Guerra, S. Polymer 2000, 41, 4869-4879.

(21) Kimura, H.; Yoshinari, T.; Takeishi, M. Polym. J. 1999, $31,388-392$.

(22) Dhamaniya, S.; Jacob, J. Polymer 2010, 51, 5392-5399.

(23) Gómez, R.; Varela, O. Macromolecules 2009, 42, 8112-8117.

(24) Bueno, M.; Galbis, J. A.; García-Martín, M. G.; DePaz, M. V.; Zamora, F.; Muñoz-Guerra, S. J. Polym. Sci., Polym. Chem. 1995, 33, 299.

(25) Maglio, G.; Marchetta, C.; Botta, A.; Palumbo, R.; Pracella, M. Eur. Polym. J. 1979, 15, 695-699.

(26) Brandrup, J.; Inmergut, E. H.; Grulke, E. A. Polymer Handbook, 4th ed.; Wiley: New York, 1999.

(27) Braun, D.; Bergmann, M. J. Prakt. Chem. 1992, 334, 298-310.

(28) Okada, M.; Tsunoda, K.; Tachikawa, K.; Aoi, K. J. Appl. Polym. Sci. 2000, 77, 338-346.

(29) Ruiz-Donaire, P.; Bou, J.; Muñoz-Guerra, S.; Rodríguez-Galán, A. J. Appl. Polym. Sci. 1995, 58, 41-54.

(30) Zamora, F.; Hakkou, K.; Muñoz-Guerra, S.; Galbis, J. A. Polym. Degrad. Stab. 2006, 91, 2654-2659.

(31) De Paz, M. V.; Marín, R.; Zamora, F.; Hakkou, K.; Alla, A.; Galbis, J. A.; Muñoz-Guerra, S. J. Polym. Sci., Polym. Chem. 2007, 45, 4109-4117.

(32) Okada, M.; Okada, Y.; Tao, A.; Aoi, K. J. Appl. Polym. Sci. 1996, 62, 2257-2265.

(33) Okada, M.; Tachikawa, K.; Aoi, K. J. Polym. Sci., Polym. Chem. 1997, 35, 2729-2737.

(34) Okada, M.; Tachikawa, K.; Aoi, K. J. Appl. Polym. Sci. 1999, 74, 3342-3350.

(35) Smith, M. B.; March, J. March's Advanced Organic Chemistry, 6th ed.; Wiley-Interscience: Hoboken, NJ, 2007; pp 523, 1270.

\section{NOTE ADDED AFTER ASAP PUBLICATION}

This article posted ASAP on May 25, 2011. It was discovered that the bicyclic acetal was not 2,4:3,5 as first formulated, but rather $2,3: 4,5$. This change affects the abstract, paragraph 3 in the Introduction, paragraphs 1, 3, 4, 5, 6, 7 in the Experimental Section, paragraphs 1, 5, 12 in the Results and Discussion, and the Conclusions paragraph. Other changes include the Table of Contents graphic, Figures 1, 2, 3, 11, 12, and the Supporting Information file. The corrected version posted on June 23, 2011. 